\title{
Experimental Study on the Pile-Soil Synergistic Mechanism of Composite Foundation with Rigid Long and Short Piles
}

\author{
Yuancheng Guo $\mathbb{D},{ }^{1}$ Chenyu Lv $\mathbb{D},{ }^{1}$ Siqiang Hou $\mathbb{D},{ }^{2,3}$ and Yunlong Liu $\mathbb{D}^{1}$ \\ ${ }^{1}$ School of Civil Engineering, Zhengzhou University, Zhengzhou 450001, China \\ ${ }^{2}$ School of Civil Mechanics and Safety Engineering, Zhengzhou University, Zhengzhou 450001, China \\ ${ }^{3}$ Henan Urban Planning and Design Research Institute Co. Ltd., Zhengzhou 450001, China \\ Correspondence should be addressed to Siqiang Hou; siqiang@gs.zzu.edu.cn
}

Received 20 November 2020; Revised 10 April 2021; Accepted 16 April 2021; Published 4 May 2021

Academic Editor: Giovanni Garcea

Copyright (c) 2021 Yuancheng Guo et al. This is an open access article distributed under the Creative Commons Attribution License, which permits unrestricted use, distribution, and reproduction in any medium, provided the original work is properly cited.

\begin{abstract}
The rigid long-short-pile composite foundation has been increasingly used as an effective and low-cost reinforcement method. The pile-soil interaction in this foundation type is more complicated than that in the equal-length pile composite foundation. In this study, several physical model tests were conducted to investigate the pile-soil synergistic mechanism of the rigid long-short-pile composite foundation. A comparative analysis was conducted of the static load test data of single-pile and long-short pile composite foundations to assess the load-bearing characteristics and stiffness evolution of the composite foundation and pile-soil unit. The result indicated a positive correlation between the pile length and the overall bearing capacity of the single-pile composite foundation. The overall stiffness of the four-pile composite foundation was lower than that of the single-pile composite foundation due to an increase in the areas of the soil stress and the pull-down effect caused by multiple piles. The long pile exerted a greater influence on the overall settlement than the short pile. In addition, the correction coefficients were obtained to determine the pile-soil stiffness of the four-pile composite foundation based on that of the single-pile composite foundation, providing a theoretical reference for the optimal design of composite foundations.
\end{abstract}

\section{Introduction}

A long-short-pile composite foundation bears the load jointly by piles of different lengths and the soil between the piles. The pile tips of the long and short piles are located in bearing layers of different depths, thus improving the bearing capacity of the composite foundation and reducing foundation settlement. This foundation type solves several engineering problems, is economical, and has been widely used in practical engineering $[1,2]$. Compared with the composite foundation with equallength piles, the pile-soil interaction of the long-short-pile composite foundation is more complicated due to the combination of different pile types [3, 4]. In traditional design, the action mechanism of different pile types and soils is comprehensively described by the bearing capacity coefficient obtained from experiments. The working mechanism of the pile-soil interaction is challenging to determine, because the efficiency factors are independent of the components [5]. The bearing capacity of the rigid long-short pile composite foundation is generally determined by conducting static load tests on long-pile and short-pile composite foundations, respectively. In addition, the bearing capacity can be determined by using the weighted average of the long-pile and short-pile areas as the bearing capacity characteristic value of rigid long-short pile composite foundations. This method reduces the load requirements in the field load test. However, the deformation stiffness values of the long pile, short pile, and the soil between the piles are different under a vertical load. Therefore, safety risks are associated with using the weighted average of the bearing capacity of rigid long-short-pile composite foundations.

The theoretical basis of the pile-soil interaction mechanism has been derived primarily from studies of pile foundations [6-8]. However, the stress state of the soil in a pile foundation is 
quite different from that of the composite foundation. The soil in the composite foundation is subjected to the load transmitted by a cushion [9], and the load-sharing rate is significantly higher than that of the soil around the pile in the pile foundation. Previous studies used the finite element method to verify the reliability of a discrete element simulation of sand media and investigated the stress state and load transfer of the long-short pile composite foundation by changing the parameters, such as the pile length and cushion modulus [10-12]. Theoretical analyses have mainly focused on analysis methods. Scholars analyzed the formation mechanism and mechanical behavior of soil arches using the common composite modulus method of integral analysis and the element analysis method of the pile foundation. In addition, the pile-soil stress ratio was determined for different pile-soil parameters [13-18]. Some scholars introduced new analysis methods and examined the pile-soil composite foundation from different angles, thus improving traditional frameworks $[19,20]$. Furthermore, researchers conducted field tests [21-23] and indoor model tests $[24,25]$ to obtain the working characteristics and evolution of the parameters of composite foundations under different geological conditions, different cushion thicknesses, and different pile conditions. The interaction between the rigid pile composite foundation and the base was analyzed. Liu assumed that the capped pile and the soil under the cap shared the load and the settlement; finite element software was used to deduce the equation describing the settlement of the capped pile composite foundation [26]. And some scholars have studied that the ground water table and lateral soil movement will also affect the behavior of long and short piles [27, 28]. However, current research on rigid long-short-pile composite foundations is mostly limited to the analysis of the bearing capacity and the mechanical characteristics of long piles, short piles, and the soil $[29,30]$, and studies on the stiffness changes of longshort-pile composite foundations are lacking. Although many studies focused on the efficiency coefficients, few have analyzed the relationship between the efficiency coefficients and the load and pile length; thus, further research is required in this area.

The main purpose of this study is to analyze the pile-soil interaction mechanism in a composite foundation. A series of static load tests of composite foundations are conducted to analyze the basic force state of a rigid long-short pile composite foundation under a vertical load. The slope of the secant line between the stress and the settlement on the top of the pile-soil element is regarded as the stiffness of the pile-soil element. The change in the overall stiffness and pile element stiffness is also crucial. The load sharing of the composite foundation and the pile-soil unit is analyzed under the same foundation stress and settlement to describe the load distribution and the change in stiffness. The stiffness correction coefficients of the long pile, the short pile, and the soil are obtained after calculating the stiffness of the four-pile composite foundation based on that of the single-pile composite foundation.

\section{Experimental Scheme}

2.1. Model Test System. The large test model box (Figure 1(a)) was independently developed by the Research Institution of Geotechnical Engineering at
Zhengzhou University. The model box has a dimension of $1600 \mathrm{~mm} \times 1600 \mathrm{~mm} \times 2500 \mathrm{~mm}$ and consists of two boxes $(1600 \mathrm{~mm} \times 1600 \mathrm{~mm} \times 1100 \mathrm{~mm})$ connected with highstrength bolts. The sidewall is made of a $5 \mathrm{~mm}$ thick steel plate and square steel tubing. The rear wall consists of 10 split plates made of $5 \mathrm{~mm}$ thick steel plates. The steel plates can be easily disassembled to increase or decrease the height of the rear wall for loading and unloading the soil. The distance between the loading plate and the side of the model box is more than one width of the plate; the outer diameter $(D)$ of the rigid pile was $0.1 \mathrm{~m}$, and the horizontal spacing between the pile and the sample container was designed to be no less than $6 \mathrm{D}[31,32]$. Thus, the influence of the boundary effects can be ignored. During the test, a plastic film was attached to the retaining wall before filling the box with sand to reduce the influence of the friction force on the soil pressure. The model test system is shown in Figure 1.

\subsection{Model Materials}

2.2.1. Soil. The soil was river sand obtained from the Zhengzhou area. Air-drying was used to reduce the cohesion of the sand. The water content of the soil was negligible.

The particle size distribution of the sand used in the model test is shown in Figure 2. The average particle size (d50) was $0.32 \mathrm{~mm}$, and the nonuniformity coefficient $(\mathrm{Cu})$ was 1.75. According to the classification standard of sand [33], sand with a particle size greater than $0.25 \mathrm{~mm}$ occupies more than $50 \%$ in the model test and can be classified as medium sand.

The soil was transported to the top of the model box by a conveyor belt, and the box was filled in layers. After standing for 7 days, the soil compactness and various test devices had stabilized. The compactness of each layer $(0.3 \mathrm{~m})$ was $45 \%$. The following method was used. First, the soil was filled to the end to the pile, and we calculated the mass of the soil required to fill the box to a height of $0.3 \mathrm{~m}$ with a $45 \%$ density. The correct soil amount was placed into the model box with the conveyor belt. Second, the soil was levelled to $0.3 \mathrm{~m}$ thickness, and soil samples were obtained for the density measurement to determine the final compaction degree. The soil was placed in the box in layers. Table 1 shows the physical parameters of the sand in a single short-pile composite foundation.

2.2.2. Rigid Piles. In this experiment, the prototype of the rigid pile composite foundation was a $\mathrm{C} 25$ rigid concrete pile (elastic modulus of $28 \mathrm{GPa}$, a diameter of $300 \mathrm{~mm}$, and ratio of length-diameter of 21). Based on the existing model tests, hollow aluminum tubes (elastic modulus of $72 \mathrm{GPa}$, outer diameter of $100 \mathrm{~mm}$, and thickness of $3 \mathrm{~mm}$ ) were used. The similarity ratio of the pile length was $1: 3$. The elastic modulus $(E)$ was not scaled; i.e., the similarity ratio was 1 . The advantage is that the stress does not change with the similarity ratio.

Full contact between the pile and soil ensures sufficient pile friction. The roughness of the pile body was increased by 


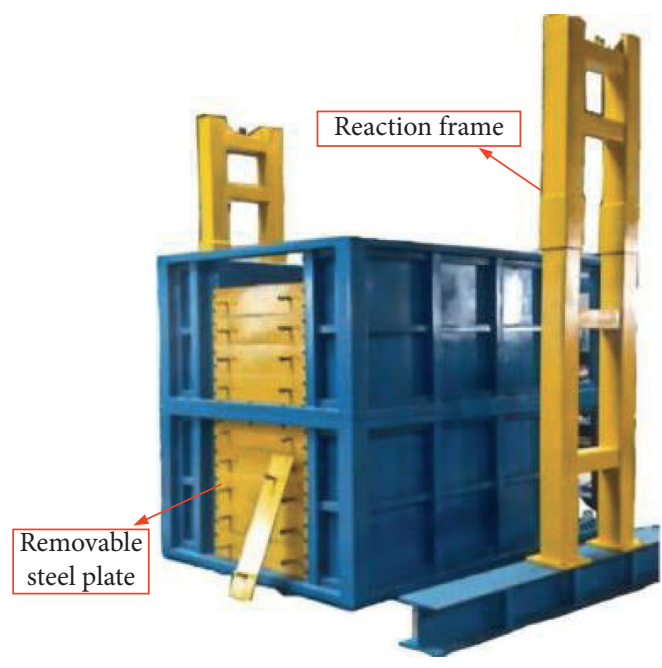

(a)

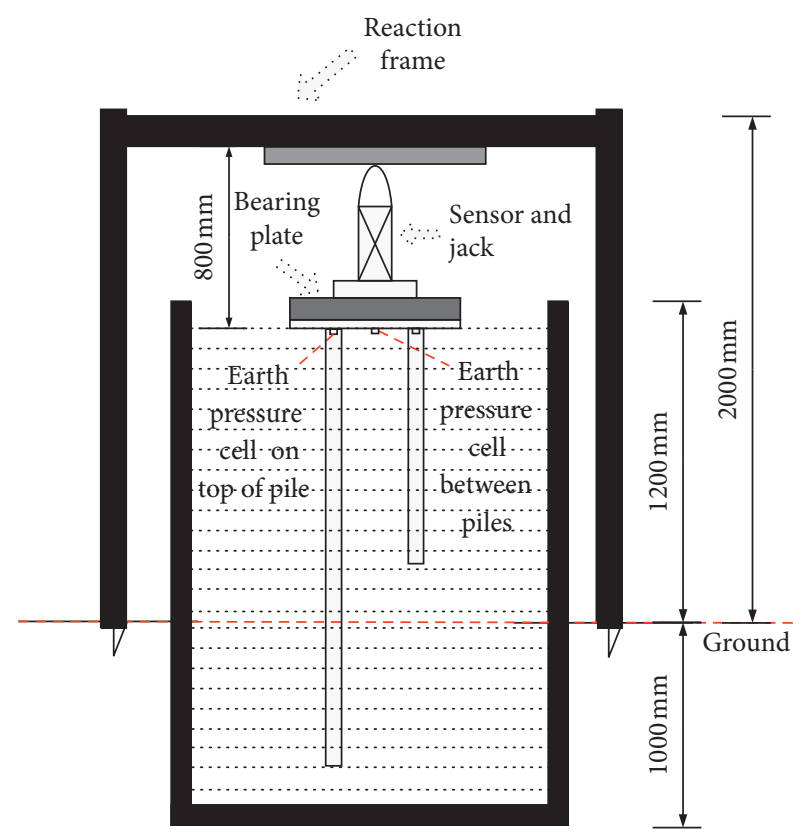

(b)

Figure 1: Model test system. (a) Model box. (b) Composite foundation model.

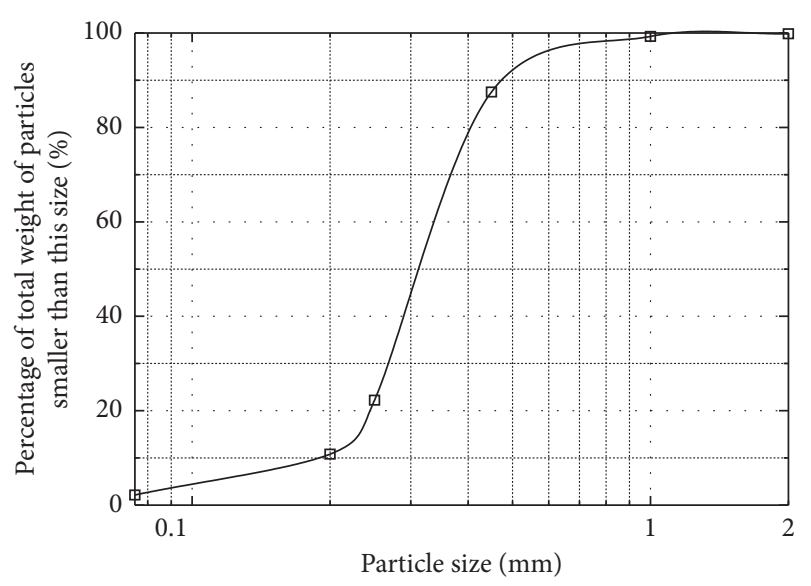

Figure 2: Particles size distribution of the sand.

TABLE 1: Physical parameters of the sand sample.

\begin{tabular}{lcccc}
\hline$D(\mathrm{~mm})$ & $\rho\left(\mathrm{g} / \mathrm{cm}^{3}\right)$ & $D_{\mathrm{r}}$ & $\varphi\left(^{\circ}\right)$ & $c(\mathrm{kPa})$ \\
\hline 0 & 1.613 & 0.38 & & \\
400 & 1.614 & 0.38 & & \\
700 & 1.622 & 0.41 & 33.42 & 6.4 \\
1000 & 1.634 & 0.45 & & \\
Average & 1.621 & 0.41 & & \\
\hline
\end{tabular}

knurling the side surface of the pile, as shown in Figure 3. According to the direct-shear test, the friction angle of the pile-soil interface was $27.3^{\circ}[34,35]$.

2.3. Strain Components of the Piles. Strain testing of the model piles was conducted using BX-120-5AA strain gauges. A pair of strain gauges was symmetrically placed on the same

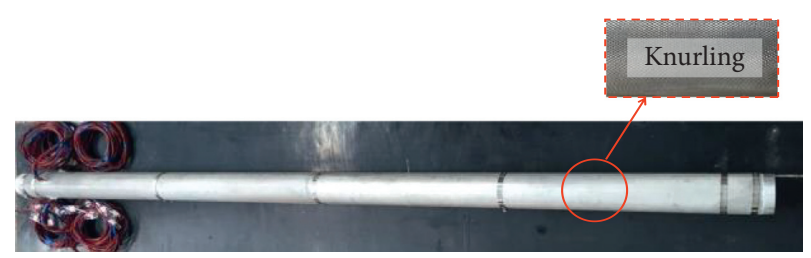

FIGURE 3: Rigid model pile used in the physical model test. Knurling was performed on the pile surface to increase the roughness of the pile.

cross section of the pile to monitor the strain and ensure the accuracy of the measurement results. The layout is shown in Figure 4 . The strain gauges were placed $200 \mathrm{~mm}$ apart and $300 \mathrm{~mm}$ apart. The strain gauges were coated with silicone for protection and were connected by a quarter bridge. The static strain gauge data were acquired by a high-speed data acquisition system.

2.4. Loading Scheme. The technical code of testing building foundation piles [36] specifies that the static load test of a composite foundation should include multistage loading. The loading device was a manual hydraulic Jack with 8-12 load levels. The maximum load should not be less than twice the value of the bearing capacity required by design, i.e., not less than the ultimate bearing capacity. According to existing research results, we estimated that the loading capacity of the single-short-pile composite foundation should be about $120 \mathrm{kPa}$, that of the single-long-pile composite foundation should be about $150 \mathrm{kPa}$, and that of the four-pile composite foundation should be about $135 \mathrm{kPa}$. According to the code [36], when the settlement reaches $1 \% \sim 1.5 \%$ of the width of the loading plate, the loading capacity is used as the 


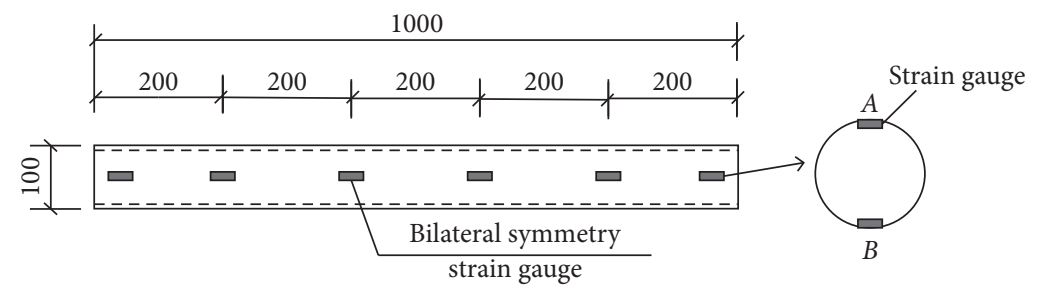

(a)

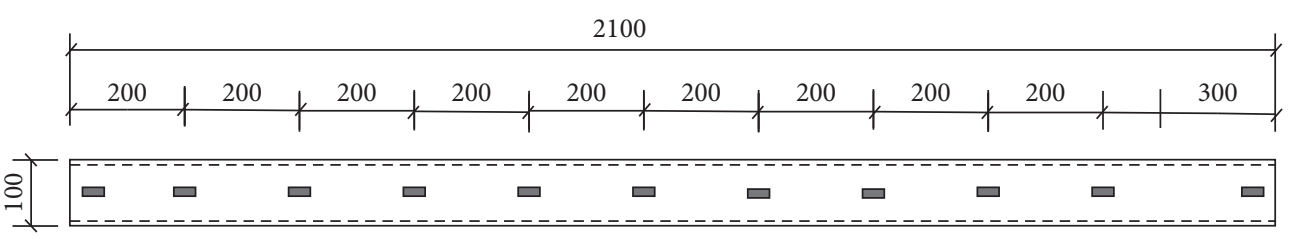

(b)

FIgURE 4: Location of the strain gauges on the short and long piles. (a) Short pile. (b) Long pile.

characteristic value of the bearing capacity of the composite foundation. In the actual experiment, the loading was stopped when the displacement reached $1 \%$ of the width of the loading plate. The test device is shown in Figure 5.

The CM-2B static data acquisition instrument was used. During the loading process, the data obtained from the strain gauges, displacement gauges, earth pressure boxes, and pressure sensors were collected automatically in realtime.

The test was conducted under three working conditions, as shown in Table 2. The four-pile composite foundation had a square configuration, and the spacing of the long and short piles was 3 times the diameter of the piles (Figure 6). The pile-soil stress ratio, pile-soil load sharing ratio, pile side friction, and the stress difference of the pile end and pile top between the single-pile and four-pile composite foundations were analyzed. The interaction between the pile stiffness and pile load sharing was also determined.

\section{Results}

3.1. The Single-Pile Composite Foundation. The single-pile composite foundation test was divided into two groups: the single-short-pile composite foundation and the single-longpile composite foundation tests.

3.1.1. Analysis of the Load-Settlement of the Two Single-Pile Composite Foundations. Figure 7 shows the load settlement (P-S) curves of the two single-pile composite foundations. The P-S curve is linear when the load is small. As the load increases, the curve becomes nonlinear. The short-pile composite foundation reaches the characteristic value of the bearing capacity faster than the long-pile composite foundation under the same load conditions.

The load capacity of the pile top and the resistance of the pile tip under different settlement conditions can be derived from the test. The load capacity curves of the pile end and pile top show different behaviours of the single-pile composite foundation; however, the settlement generally increases with an increase in the vertical load (Figure 8).

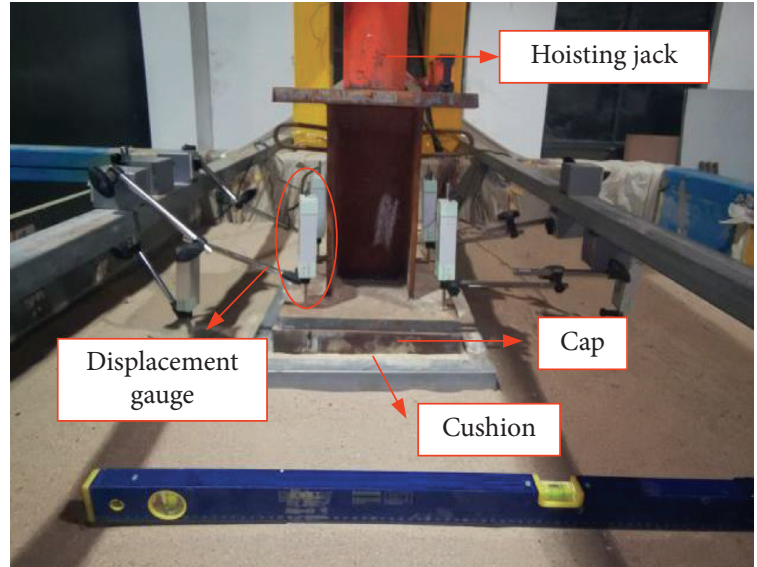

Figure 5: Test device.

Unlike in the long-pile composite foundation, an inflexion point is observed at $0.4 \mathrm{~mm}$ settlement in the short-pile composite foundation. Under the same settlement conditions, the load capacity of the pile tip increases with increasing the length of the pile. The lateral area and pile length of the short pile are smaller than those of the long pile; thus, the pile tip load capacity is within the critical depth range of the tip resistance. Therefore, under the same settlement conditions of the pile top, the pile top stress of the long-pile composite foundation is greater than that of the short-pile composite foundation. The secant slope of the curve is regarded as the integral stiffness of the composite foundation. The results indicate that the integral stiffness of the short-pile composite foundation is lower than that of the long-pile composite foundation.

3.1.2. Analysis of the Pile-Soil Stress Ratio of the Two SinglePile Composite Foundations. The pile-soil stress ratio of the short-pile composite foundation is much smaller than that of the long-pile composite foundation, and the foundation stress ratio stabilizes at about 9.5 after reaching $70 \mathrm{kPa}$ (Figure 9). The pile-soil stress ratio of the long-pile 
TABLE 2: Test groups.

\begin{tabular}{lccc}
\hline Types & Cushion thickness $(\mathrm{mm})$ & Pile length $(\mathrm{mm})$ & Pile diameter $(\mathrm{mm})$ \\
\hline Single-short-pile & 50 & 1000 & 100 \\
Single-long-pile & 50 & 2100 & 100 \\
Four-long-short piles & 50 & $1000 / 2100$ & 100 \\
\hline
\end{tabular}

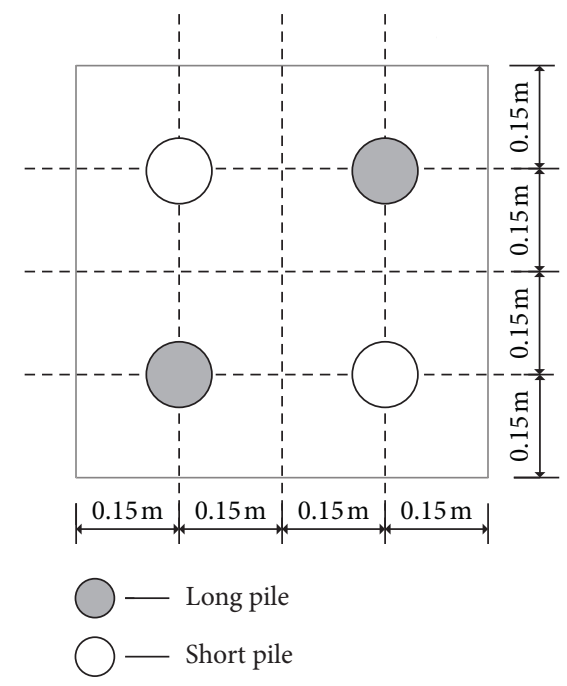

FIGURE 6: The four piles configuration.

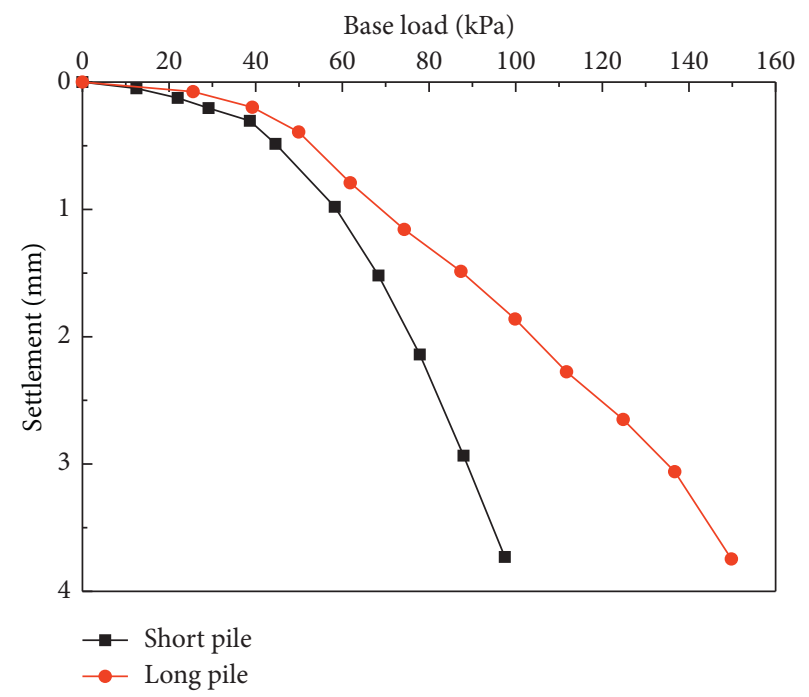

FIGURE 7: Load settlement curves of the two single-pile composite foundations.

composite foundation shows an increasing trend, indicating that the stress ratio may be higher under the maximum load.

3.1.3. Analysis of the Axial Force and Skin Friction of the Two Single-Pile Composite Foundations. The axial force increases with increasing load (Figure 10). The axial force first increases and then decreases along the pile length, which is in agreement with the axial force response of general composite foundations. The maximum axial forces are about $5000 \mathrm{~N}$

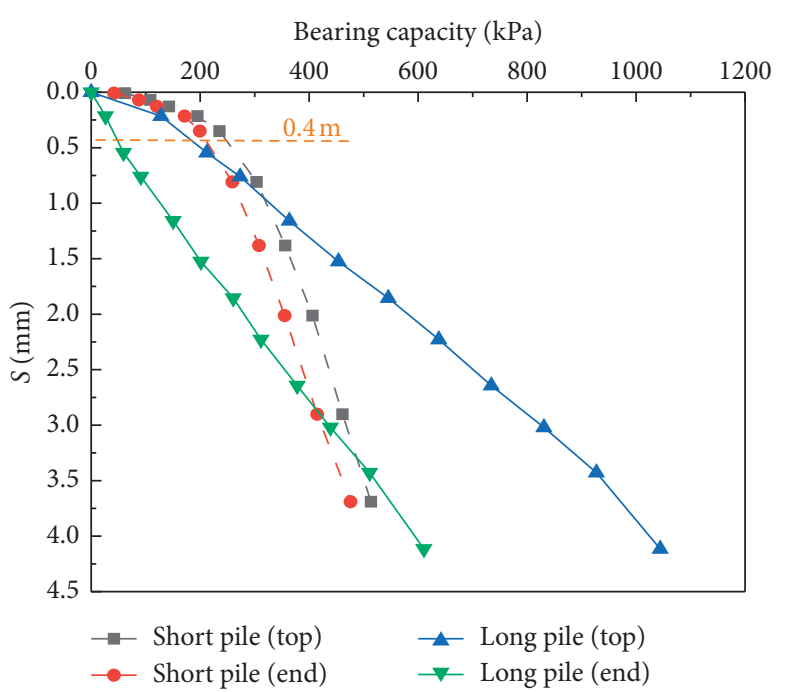

FIGURE 8: Bearing capacity curves of the two single-pile composite foundations.

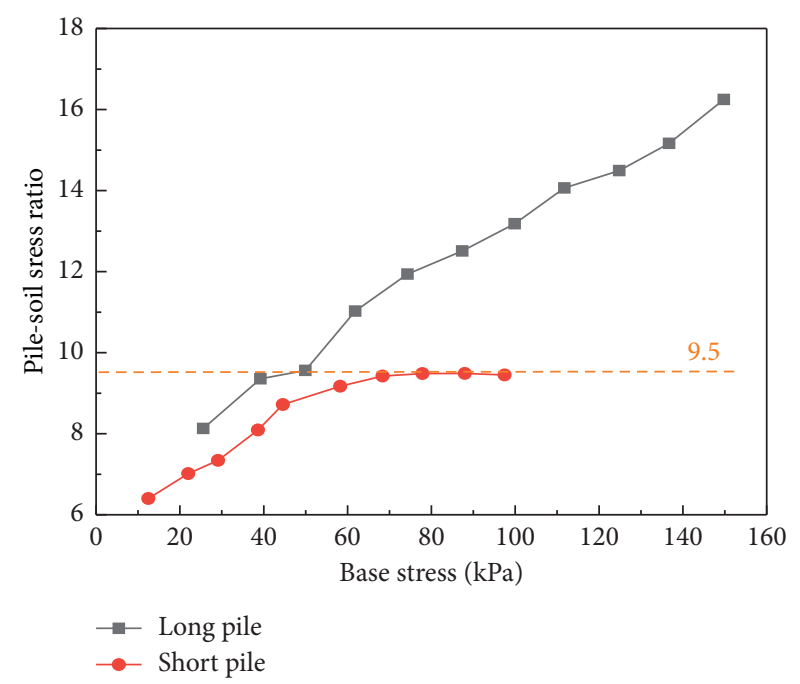

Figure 9: Pile-soil stress ratio curves of the two single-pile composite foundations.

(short pile) and $12,000 \mathrm{~N}$ (long pile). The positive and negative extreme values of the side friction of the short piles are similar (about 10 15 kPa) (Figure 11(a)). The long pile's maximum value of negative (positive) friction is about $40 \mathrm{kPa}(20 \sim 25 \mathrm{kPa})$. The additional horizontal stress is larger in the upper part than the lower part due to the stress concentration in the upper part, whereas stress diffusion occurs in the lower part. Thus, the maximum negative friction of the long pile is greater than the maximum positive friction at the neutral point. Furthermore, the position of the 


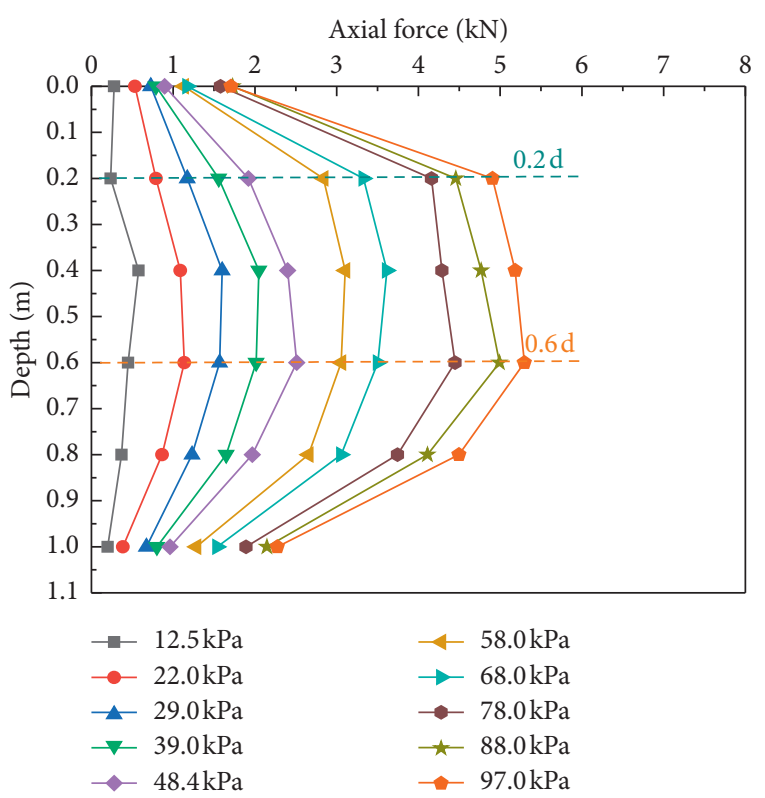

(a)

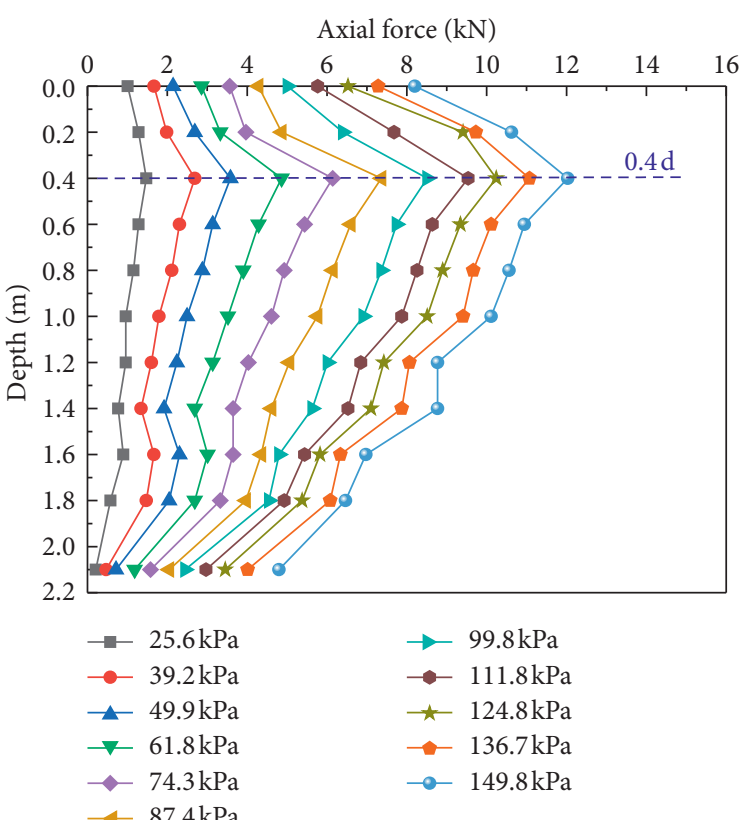

(b)

FIGURE 10: Axial stress of the single short-pile (a) and long-pile (b) composite foundations.

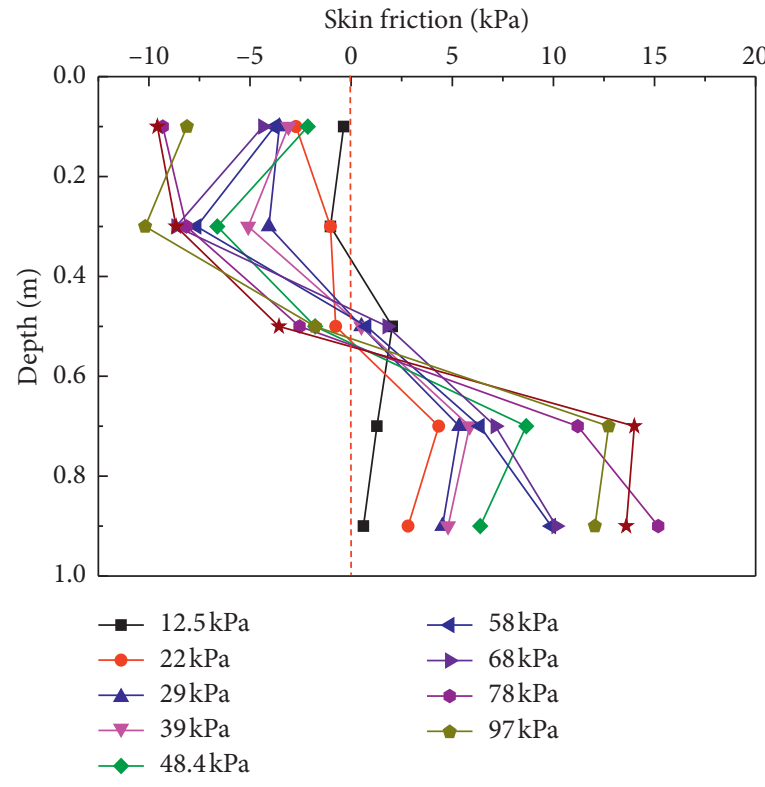

(a)

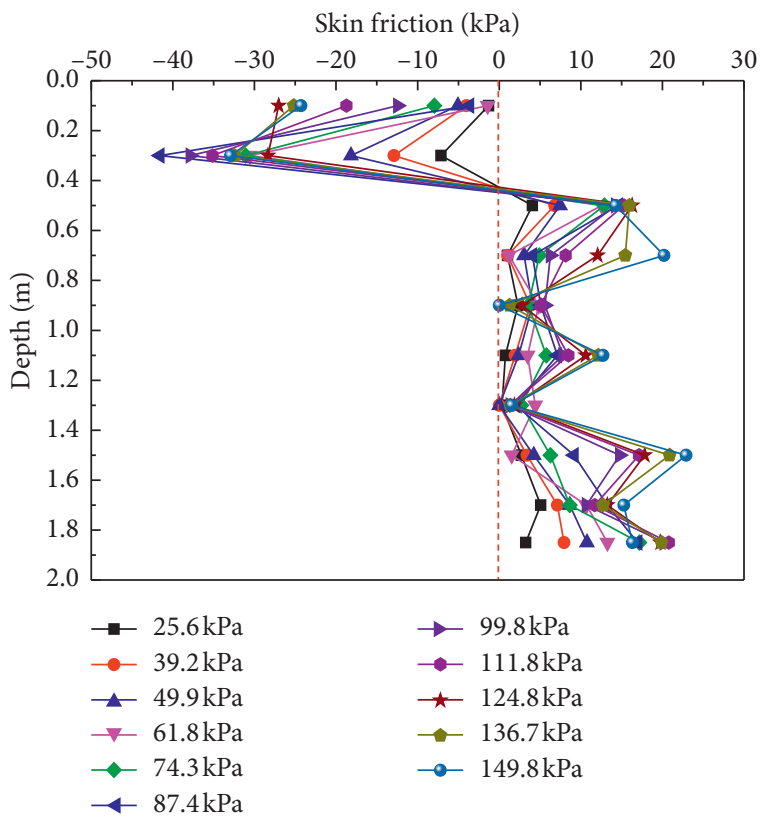

(b)

FIGURE 11: Skin friction of the single short-pile (a) and long-pile (b) composite foundation.

neutral point, which is an important index in a composite foundation, is significantly correlated with the mechanical properties of the piles. The neutral points of the short-pile composite foundation are located at $0.4 \sim 0.6 \mathrm{~m}$, which is $0.4 \sim 0.6$ times the pile length. The neutral points of the longpile composite foundation are concentrated around $0.5 \mathrm{~m}$ or 0.24 times the pile length. The reason may be that the loading of the short-pile composite foundation is small, the upper soil is still relatively loose, and the skin friction and the strain gauge sensitivity are relatively low. Therefore, when the absolute errors of the long piles and short piles are similar, the relative error of the short pile is relatively large.

The characteristic value of the bearing capacity of the long-pile composite foundation is about $50 \%$ higher than that of the short-pile composite foundation. An increase in the pile length results in an increase in the skin friction of 
about 1.1 times theoretically. However, the load capacity of the long pile is far less than $50 \%$ of the load capacity of the short pile. Comprehensive analysis indicates that the reason is that the buried depth is shallow for a short pile, and the pile tip resistance increases linearly with increasing depth. Increasing the pile length increases the contact area of the pile-soil side surface, the overall side friction of the pile, and the load capacity of the pile end, which increases linearly. Second, increasing the bearing capacity increases the load borne by the soil and further increases the horizontal stress of the pile side. In addition, the cushion layer transfers the force tightly to the soil and increases the horizontal Earth pressure coefficient, which further increases the side friction of the long pile. The negative skin friction increases significantly.

Since the positive skin friction in the lower part is relatively far from the pile top, the increase is small. This result indicates that the rate of increase in the bearing capacity of the single-long-pile composite foundation is lower than the amplification in the pile length. Therefore, when the pile length is less than the critical pile length of the tip resistance, increasing the pile length can significantly improve the overall bearing capacity, but the increase in the bearing capacity is still less than the increase in the pile length.

\subsection{Four-Pile Composite Foundation}

3.2.1. Analysis of the Bearing Capacity and Contribution Rate of the Pile Tips of the Four-Pile Composite Foundation. The parameters of the long piles and short piles in the four-long-short-pile composite foundation are the same as those of the single-pile composite foundation. The long and short piles are arranged alternately. In the longshort-pile composite foundation, the main function of the long pile is to transfer the load to the depth of the foundation through the pile and reduce the deformation of the compressed soil layer. The short pile passes through the upper soft soil layer to increase the bearing capacity of the upper soil layer. Figures 12 and 13 show the load capacity at the ends and tops of the long and short pile and the contribution rate of the pile tips, respectively, for the four-pile composite foundation.

In the four-pile composite foundation, the bearing capacities of the long piles and short piles show increasing trends. Due to the combined support of the piles, there is no elastic-plastic boundary point. The load shared by the single long pile is about 2.5 times that of the single short pile. The load at the end of the long pile is about 2.2 times that of the short pile tips. The contribution rate of the pile end increases with the base stress, and the maximum contribution rate is $57 \%$ for the short pile and $49 \%$ for the long pile. The contribution rate of the short pile tips is greater than that of the long pile, because the pile tip area is the same, but the lateral areas are quite different for the two different pile types. Furthermore, because the buried depth is relatively shallow, and the pile tip is above the critical buried depth, the load capacity of the pile tip is approximately proportional to

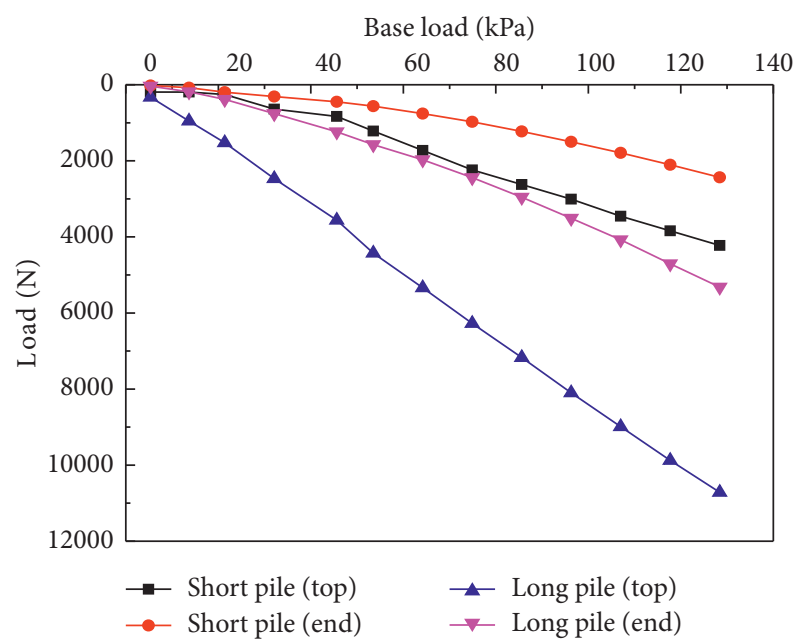

FIgURE 12: Load capacity of the long pile and short pile ends and tops in the four-pile composite foundation.

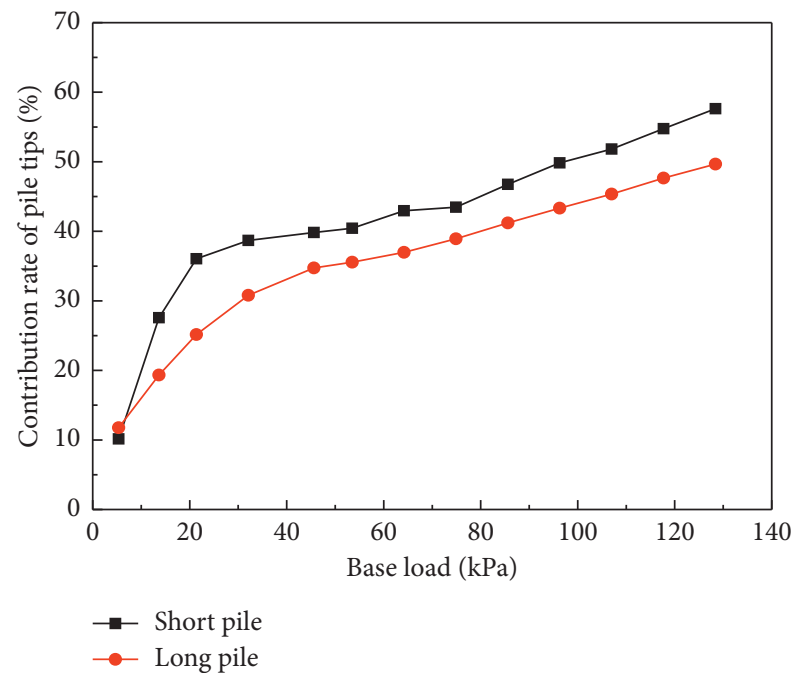

Figure 13: Contribution rate of the pile tips in the four-pile composite foundation.

the depth. Therefore, the difference in the contribution rate between the long and short pile tips in the four-pile composite foundations is not significant. In addition, the bearing capacity of the four-pile composite foundation is larger than that of the single-short-pile composite foundation, and slightly smaller than that of the single-long-pile composite foundation. As a result, the additional horizontal stress at the pile interface of the four-pile composite foundation is larger than that of the short-pile composite foundation, and slightly smaller than that of the long-pile composite foundation. Therefore, the lateral friction of the short pile is larger than that of the single-pile composite foundation. Similarly, the rules of the long pile can be obtained. Hence, in the four-pile composite foundation, the contribution rate of the short pile tips is lower than that of the single-short-pile composite foundation, and the contribution rate of the long pile tips is larger than that of the single-long-pile composite foundation. 
3.2.2. Analysis of Pile-Soil Stress Ratio and Load Sharing Ratio of the Four-Pile Foundation. The pile-soil stress ratio of the short piles and long piles in the four-pile composite foundation gradually increases with the foundation stress (Figure 14). The long pile curve has an inflexion point when the base stress is about $50 \mathrm{kPa}$. Figure 15 shows that the soil and pile both share the load. The load-sharing ratio of the soil decreases initially with an increase in the base stress and then stabilizes.

\section{Discussion}

4.1. Comparative Analysis of Composite Foundations. Figure 16 shows the load F-S curve of the single-pile composite foundation and four-pile composite foundation. The integral stiffness of the composite foundation (the secant slope of the foundation stress and substrate settlement) in descending order is single-long-pile composite foundation, average value of two single-pile composite foundations, single-short-pile composite foundation, and four-long-short pile composite foundation. The global stiffness of the fourpile composite foundation is about $20 \sim 30 \%$ lower than that of the average stiffness of two single- pile composite foundations. This result shows that the stiffness of each component of the four-pile composite foundation differs from that of the single-pile composite foundation. Thus, it is necessary to analyze the load capacity of the short pile, long pile, and soil separately.

Traditional design concepts are mostly based on the bearing capacity as a design criterion. Due to increasing development, more design criteria are based on the settlement. However, there are relatively few studies on the settlement criteria of rigid long-short pile composite foundations. Since the bearing characteristics of a pile are closely related to the settlement, it is necessary to analyze the bearing characteristics of the soil and piles separately because the foundation stress and foundation settlement are independent variables.

Under the same foundation stress condition, the load shared by the soil of the four-pile composite foundation is greater than that of the single-short pile composite foundation (Figure 17(a)). However, under the same foundation settlement conditions, the opposite trend is observed (Figure 17(b)). The stiffness of the soil unit is about $20 \sim 30 \%$ lower in the four-pile composite than the single-pile composite foundation. The reason is the different stress mechanisms of the soil in the two composite foundations. The rigidity of the single-pile composite foundation is relatively large, because the soil around the pile is connected to and restricted by the external soil. The soil of the four-pile composite foundation is located between the piles, and the load area of the four-pile composite foundation is larger than that of single-pile composite foundation. The soil in the middle is less constrained, resulting in low stiffness of the composite foundation. The soil stress increases; i.e., the change in the soil stress is inconsistent with the stiffness distribution. The reason is that the overall stiffness of the four-pile composite foundation is relatively low, and the settlement increases under the same

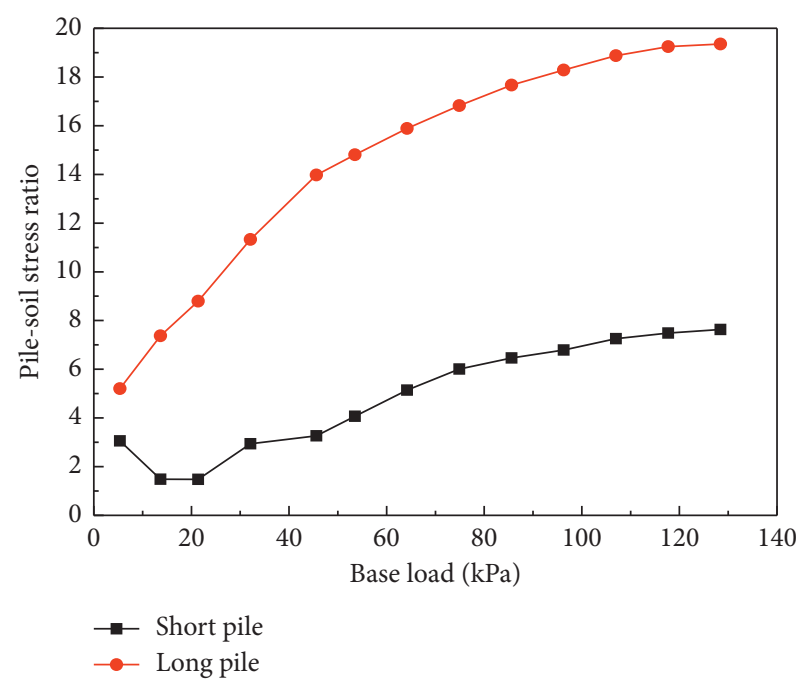

FIgURE 14: Pile-soil stress ratio of the four-pile composite foundation.

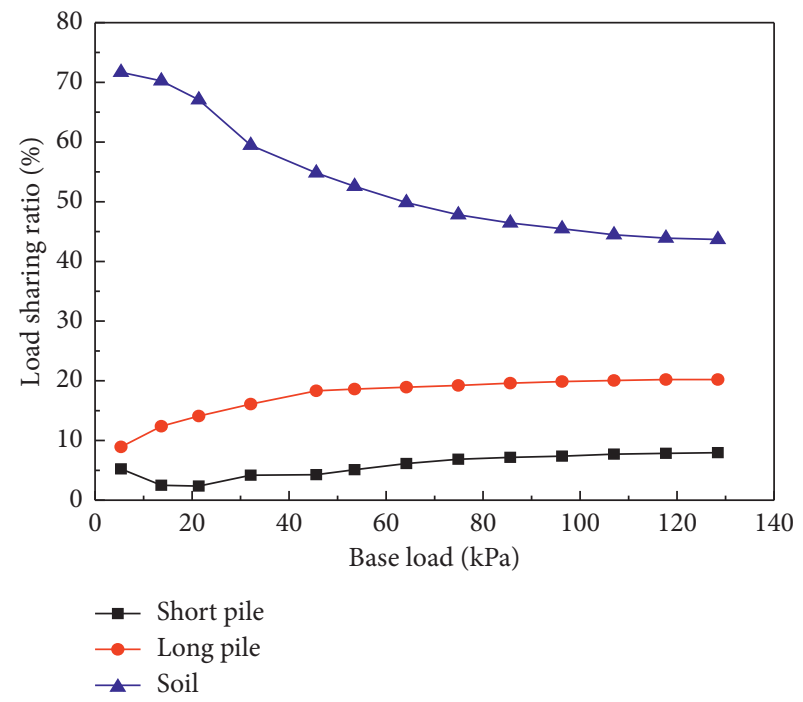

Figure 15: Load sharing ratio of the four-pile composite foundation.

foundation stress conditions. Thus, the performance of the soil increases.

A comparison of Figures 18(a) and 18(b) shows that, under the same foundation settlement conditions, the load sharing of the short piles of the four-pile composite foundation is less than that of the single-short-pile composite foundation. The load sharing of the long piles in the four-pile composite foundation is greater than that of the single-long pile composite foundation. The stiffness of the short pile unit (long pile) is $30 \%-40 \%$ lower $(10 \%-$ $15 \%$ lower) in the four-pile composite foundation than the single-pile composite foundation. Although the overall stiffness of the four-pile composite foundation is low, the settlement under the same load is larger than that of the single-pile composite foundation. The pile units in the four-pile composite foundation are fully mobilized. 


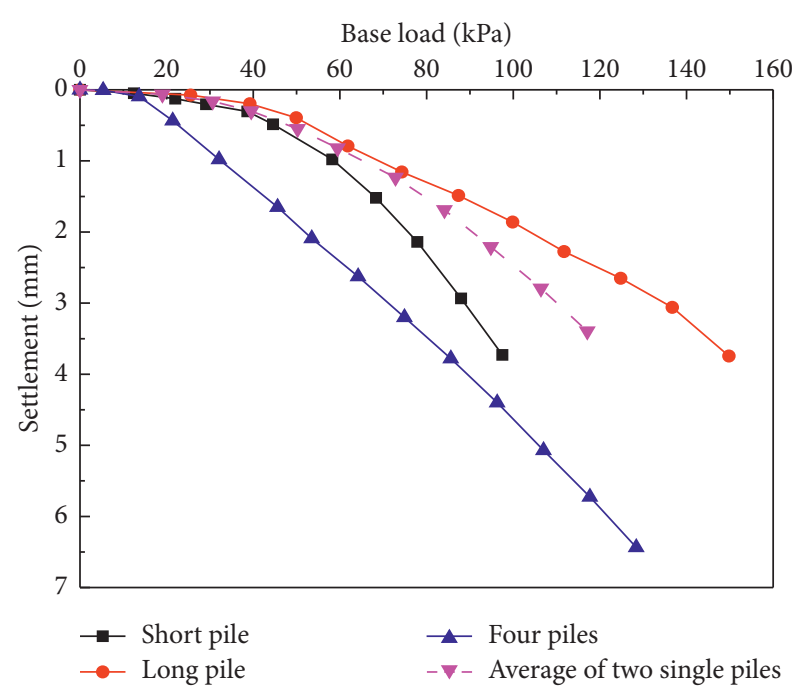

FIGURE 16: Load settlement curves of the single-pile composite foundation and four-pile composite foundation.

Therefore, although the stiffness is reduced, the load sharing has improved. Under the same load conditions, the top load of the long pile of the four-pile composite foundation is greater than that of the single-pile composite foundation. Nevertheless, the short pile top load of the four-pile composite foundation is still smaller than that of the single-pile composite foundation, although the difference is relatively small. This result shows that the long pile is more sensitive to the overall settlement, and the range is larger than that of the short pile.

4.2. Mechanism of Pile-Soil Interaction in Rigid Long and Short Piles Composite Foundation. The results indicate that when the composite foundation is changed from a single pile to four piles, substantial differences are observed in the mechanical properties and stiffness changes between the long piles, and short piles, as well as the load-sharing ratio of the soil.

First, the overall changes are analyzed from the perspective of interaction. The pile replacement ratio does not change from the single-pile composite foundation to the four-pile composite foundation, but the soil area increases four times. Under the same soil top stress conditions, the settlement of the soil increases, and the unit stiffness of the soil decreases with increasing soil area. It is difficult to measure the settlement of the pile and the top of the soil in experiments; thus, it is required to consider the ratio of the load on the top of the pile to the settlement of the base to determine the stiffness of the pile element. The ratio of the stress on the top of the soil to the base settlement is regarded as the stiffness of the soil around the pile. The ratio of the base stress to the foundation settlement is regarded as the overall element stiffness.

When the stiffness of the soil element decreases, first, it weakens the overall stiffness of the four-long-short-pile composite foundation. Second, under the same foundation stress conditions, the soil exhibits more settlement, which causes additional settlement of the piles and weakens the stiffness of the pile element. On one hand, the stiffness of the pile unit decreases due to the effect of soil. On the other hand, with the increase in the number of piles from a single pile to four piles, the piles are affected by pile-pile interaction; thus, the active pile has a pull-down effect on the soil when it is stressed. This pulldown effect is transmitted to the passive pile through the soil, resulting in additional settlement of the passive pile. As a result, the stiffness of the pile body decreases, decreasing the load shared by the pile body at the same foundation settlement and reducing the overall stiffness. As a result, the foundation stress of the four-pile composite foundation is significantly lower than that of the single-pile composite foundation at the same foundation settlement.

After analyzing the load sharing and stiffness of each element of the pile-soil interaction, it can be deduced that the difference in the pile-soil bearing behaviour between the single-pile composite foundation and the four-pile composite foundation is due to load redistribution based on stiffness. In the single-pile composite foundation, there are only two parts below the cushion, i.e., the pile and the soil around the pile. According to the stiffness distribution principle, the stiffness of the long pile is greater than that of the short pile, and that of the short pile is greater than that of the soil. Therefore, in a single-pile composite foundation, the pile-soil stress ratio of the short-pile composite foundation is smaller than that of the long-pile composite foundation.

The number of piles is larger in a four-pile composite foundation than in a single-pile composite foundation. In the former, the pile area is four times the area of the single-pile composite foundation, and part of the soil is replaced with rigid piles. This mechanical model can be simplified to a stiffness spring for the analysis. The long piles, short piles, soil, and the cushion above are regarded as a column, and the element stiffness of the column is $k_{1}$, $k_{2}$, and $k_{3}$, respectively. The simplified model diagram is shown in Figure 19.

When the base stress is constant in the rigid pile composite foundation, it can be assumed that the pile element and the soil element around the pile are parallel. The single-pile composite foundation with soil area $A$ has only one pile and the soil around the pile. Under the condition of the base stress $P$, the load shared by the pile of the single-long-pile composite foundation is $P A k_{1} /$ $\left(k_{1}+k_{3}\right)$, and the load shared by the soil is $P A k_{3} /\left(k_{1}+k_{3}\right)$. Table 3 shows the load sharing of composite foundations in other cases.

According to the magnitude of $k_{1}, k_{2}$, and $k_{3}\left(k_{1}>k_{2}>k_{3}\right)$, it can be concluded that, under the same foundation stress conditions, the order of load sharing from large to small is long pile in the four-pile composite foundation, long pile in the single-pile composite foundation, short pile in the single-pile composite foundation, and short pile in the four-pile composite foundation. These results are consistent with those obtained from the experiment. 


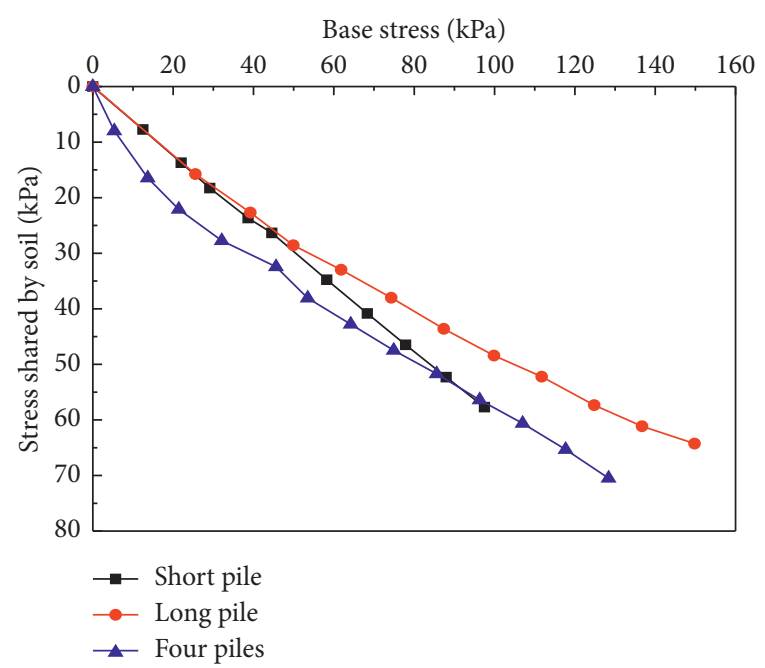

(a)

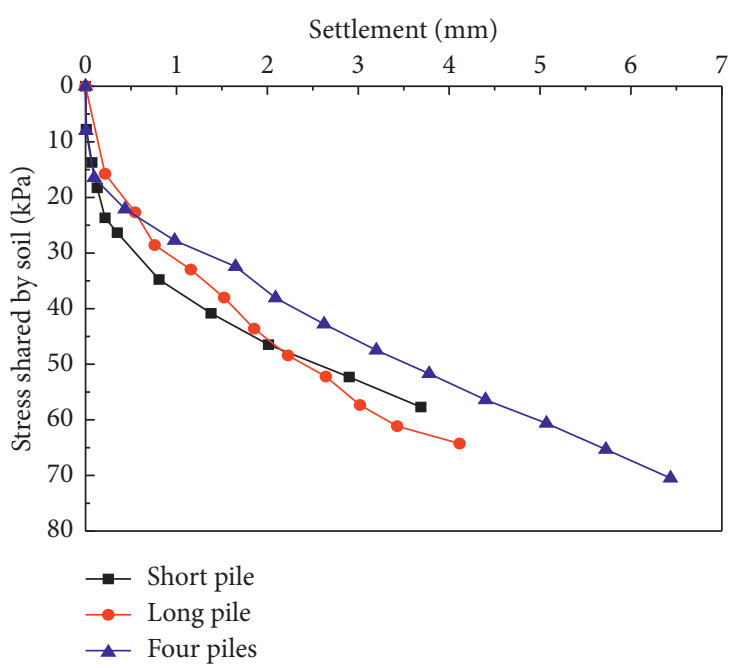

(b)

FIgURE 17: The stress shared by the soil of the single-pile composite foundations and the four-pile composite foundation. (a) Base stress. (b) Settlement.

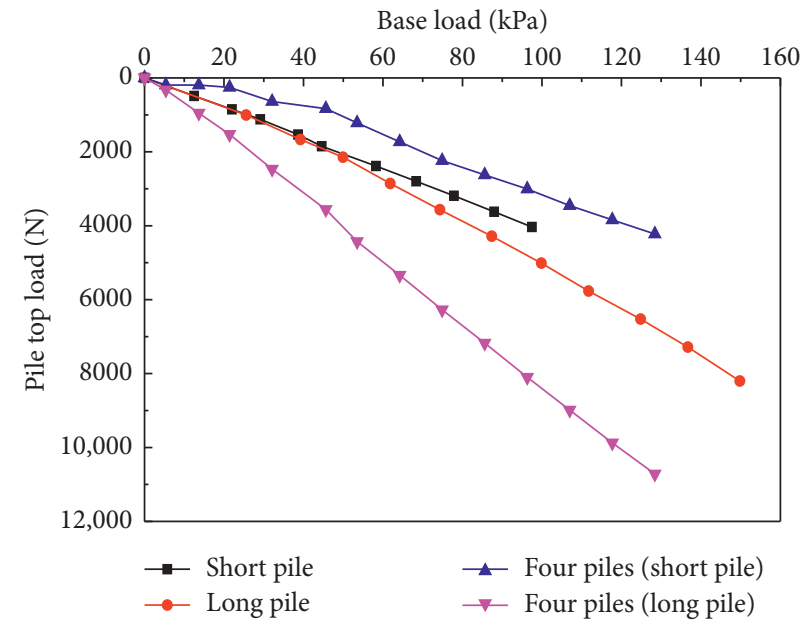

(a)

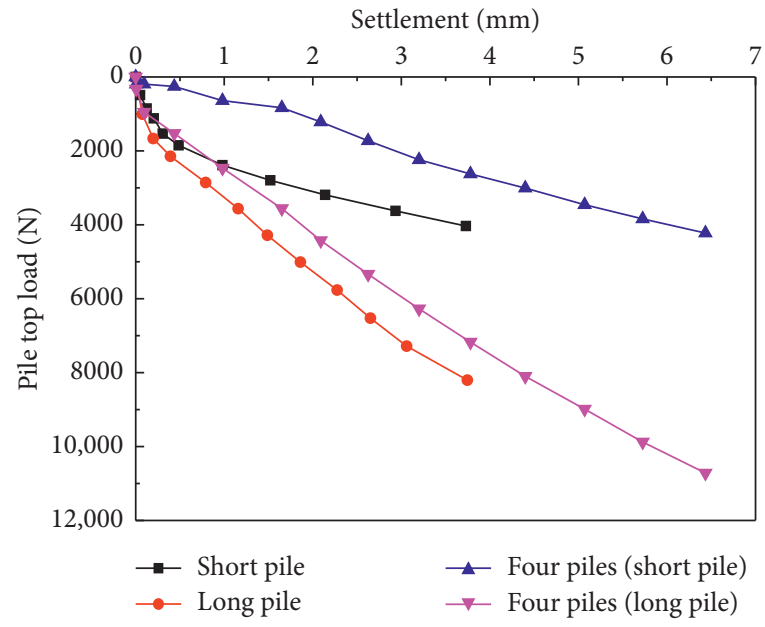

(b)

FIGURE 18: Load-sharing of the pile top of the single-pile composite foundation and the four-pile composite foundation. (a) Base load. (b) Settlement.

In this study, the stiffness correction coefficients of the long pile, short pile, and soil are calculated based on the test results. The influences of the pile number on the pile-soil unit of the composite foundation can be compared numerically. The overall stiffness correction coefficient is $0.7 \sim 0.8$, that of the short pile is about $0.6 \sim 0.7$, that of the long pile is $0.85 \sim 0.9$, and that of the soil is $0.7 \sim 0.8$.

\section{Numerical Simulation Analysis}

5.1. The Finite Element Model. The composite foundation with long and short piles shown in Figure 1 was modelled in FLAC $^{3 D}$ to conduct a 3D elastic-plastic finite element analysis using the same pile lengths and diameters as in the indoor test model. The model is shown in Figure 20. Based on the test, a natural foundation and four-pile composite foundation were added for comparative analysis. The model groups are listed in Table 4.

The material property parameters of the soil were selected by referring to the indoor model test in Section 2.2.1. The Mohr-Coulomb (M-C) model was adopted for the cushion and the soil between the piles. Since there was slippage between the soil around the piles and the contact surface of the piles, the horizontal displacement between the cushion layer and the pile was negligible. The contact between the pile and the soil around the pile was based on the M-C model, and the contact between the pile and the cushion was hard contact. The four sides of the soil constrained the normal displacement, and the bottom surface constrained the displacement in the $x, y$, and $z$ directions. Due to the steel frame restraint around the cushion in the test, a normal constraint was applied to the surrounding area. 


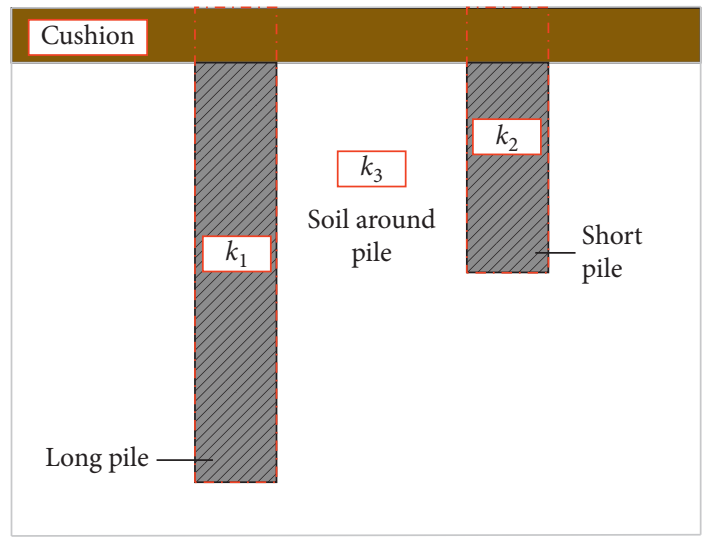

Figure 19: Simplified diagram of the four-pile composite foundation.

TABLE 3: Load sharing of composite foundation.

\begin{tabular}{lccc}
\hline Types & Long pile & Short pile & Soil \\
\hline Single-long-pile composite foundation & $P A k_{1} /\left(k_{1}+k_{3}\right)$ & & $P A k_{3} /\left(k_{1}+k_{3}\right)$ \\
Single-short-pile composite foundation & & $P A k_{2} /\left(k_{2}+k_{3}\right)$ & $P A k_{3} /\left(k_{2}+k_{3}\right)$ \\
Four-pile composite foundation & $4 P A k_{1} /\left(2 k_{1}+2 k_{2}+4 k_{3}\right)$ & $4 P A k_{2} /\left(2 k_{1}+2 k_{2}+4 k_{3}\right)$ & $4 P A k_{3} /\left(2 k_{1}+2 k_{2}+4 k_{3}\right)$ \\
\hline
\end{tabular}

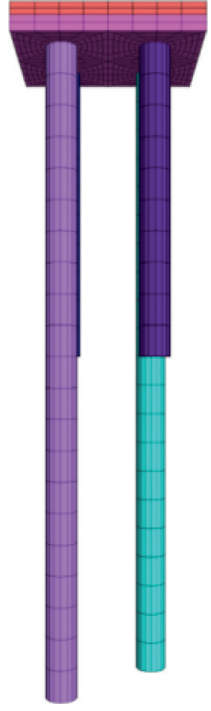

Figure 20: 3D model of the long-short pile composite foundation.

\subsection{Analysis of the Force Transmission Mechanism of the Rigid Pile Composite Foundation Based on the Change in the Pile Length}

5.2.1. Experimental Verification and Analysis of the Basic Bearing Characteristics. Figure 21 shows the load-settlement curves of the single-pile composite foundation obtained from the laboratory model test and the numerical simulation. The fit of the data is good for the two conditions. Therefore, it is concluded that the parameter setting of numerical simulation meets the requirements.

The load-settlement curves of the natural foundation, single-pile composite foundation, and four-pile composite foundation show a gradual decrease, and no elastoplastic boundary point is observed (Figure 22). The overall stiffness of the single-pile composite foundation is greater than that of the four-pile composite foundation, which is consistent with the model test result. The reason is that the soil stress state differs for the piles, and the pile body produces a pulldown effect due to the presence of multiple piles. As the load increases, the difference in stiffness between the single-pile and four-pile composite foundations is gradually decreasing. For the same number of piles, the longer the pile, or the greater the sum of the lengths of the piles, the greater the overall stiffness. The pile is an important part of the load sharing of the composite foundation; thus, the longer the pile, the greater the stiffness. The change in the soil stiffness is relatively smaller for a similar pile length; therefore, the overall stiffness of the composite foundation is greater than that of the other foundation.

5.2.2. Stiffness Change of the Pile. Figure 23 shows the change in the pile top load with increasing base stress for the four groups of composite foundations with $1.0 \mathrm{~m}$ piles. For the same base load, the load shared in descending order is $1.0 \mathrm{~m}$ four-pile composite foundation with equallength piles, $1.0 \mathrm{~m} / 1.5 \mathrm{~m}$ four-pile composite foundation, $1.0 \mathrm{~m} / 2.1 \mathrm{~m}$ four-pile composite foundation, and $1 \mathrm{~m}$ single-pile composite foundation. The load sharing of the short piles in the four-pile composite foundation is generally greater than that of the single-pile composite foundation; the longer the long pile, the smaller the load shared by the short piles. The overall rigidity of the singlepile composite foundation is greater than that of the fourpile composite foundation. At the same load, the settlement of the single-pile composite foundation and that of the short pile are small. Therefore, the load sharing of the short pile in the single-pile composite foundation is less than that of four-pile composite foundation for the same base stress. In the four-pile composite foundation, the longer the long 
TABLE 4: Model groups.

\begin{tabular}{|c|c|c|c|c|c|}
\hline & Types & Pile length $(\mathrm{m})$ & Cushion thickness $(\mathrm{mm})$ & Loading board size $(\mathrm{mm})$ & Pile diameter $(\mathrm{mm})$ \\
\hline 1 & Natural foundation & & & $300 \times 300$ & 100 \\
\hline 2 & & 1.0 & 50 & $300 \times 300$ & 100 \\
\hline 3 & Single-pile composite foundation & 1.5 & 50 & $300 \times 300$ & 100 \\
\hline 4 & & 2.1 & 50 & $300 \times 300$ & 100 \\
\hline 5 & & $1.0 / 1.0$ & 50 & $600 \times 600$ & 100 \\
\hline 6 & & $1.0 / 1.5$ & 50 & $600 \times 600$ & 100 \\
\hline 7 & Four-pile composite foundation & $1.0 / 2.1$ & 50 & $600 \times 600$ & 100 \\
\hline 8 & & $1.5 / 1.5$ & 50 & $600 \times 600$ & 100 \\
\hline 9 & & $1.5 / 2.1$ & 50 & $600 \times 600$ & 100 \\
\hline 10 & & $2.1 / 2.1$ & 50 & $600 \times 600$ & 100 \\
\hline
\end{tabular}

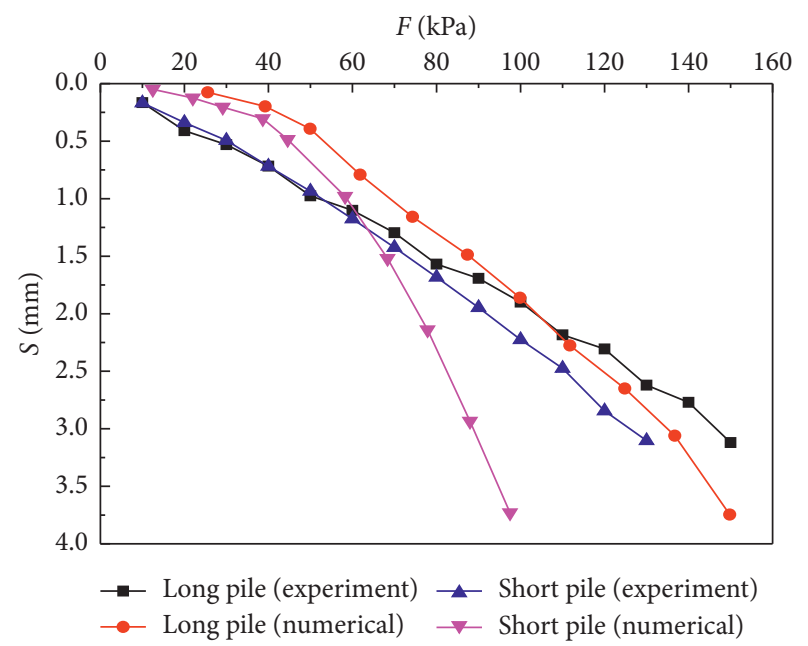

FIGURE 21: Experimental and numerical settlement results of the single-pile composite foundation.

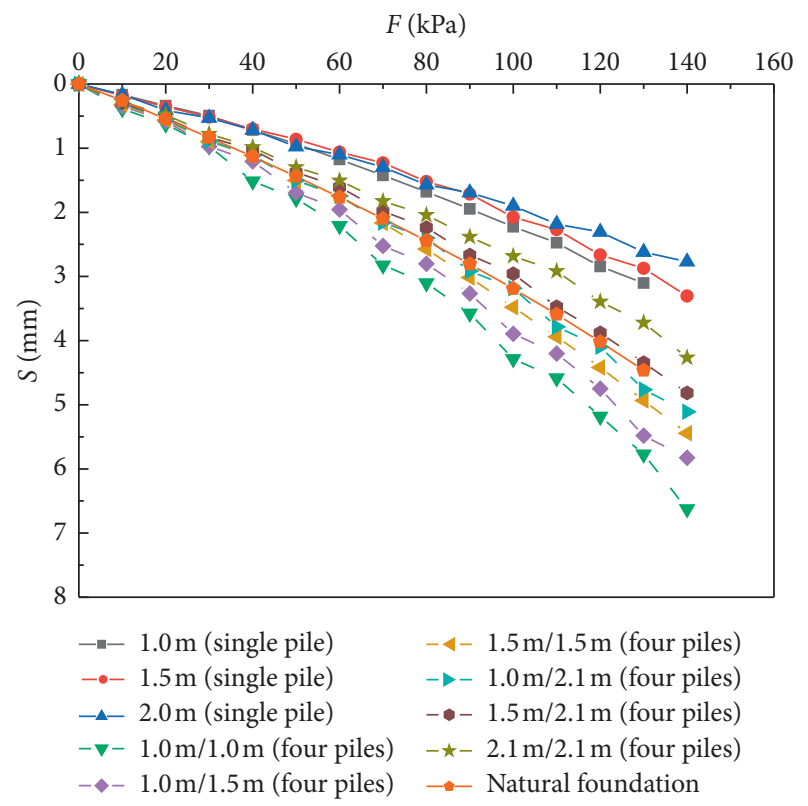

FIgURE 22: F-S curves of the composite foundations.

pile, the greater its rigidity, resulting in an increase in the load distribution of the long pile and a smaller load shared by the short pile.

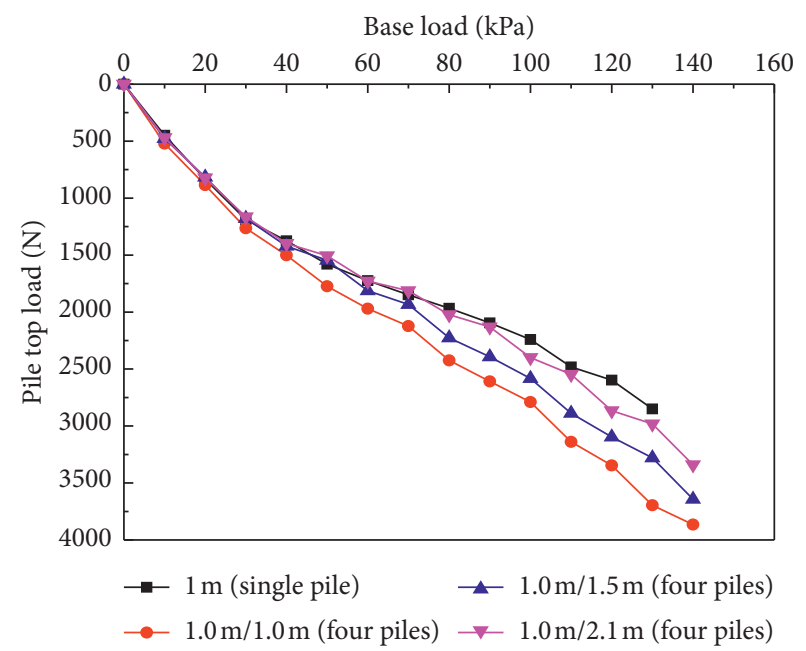

Figure 23: Pile top load of the short pile in the composite foundations.

Figure 24 shows the changes in the pile top load with increasing base stress for the four groups of composite foundations containing $2.1 \mathrm{~m}$ piles. As the stiffness of the long pile element changes, the response of the composite foundation is similar to that of the short pile element.

5.2.3. Stiffness Change of the Soil. Figure 25 shows the load sharing by the soil with increasing stress of the basement in the two cases. The load sharing of the soil in the four-pile composite foundation is less than that of the single-pile composite foundation for the same base stress condition (Figure 25(a)). In the four-pile composite foundation, the longer the long pile, the smaller the soil load sharing. The reason is that the size of the single-pile composite foundation is smaller than that of the four-pile composite foundation, and the rigidity of the soil is greater in the single-pile composite foundation. Therefore, the soil in the single-pile composite foundation bears more of the load than the four-pile composite foundation for the same foundation stress. In the four-pile composite foundation, the longer the pile body, the greater the overall stiffness, and the smaller the overall settlement for the same base stress. An increase in the rigidity of the long pile causes the long pile to bear more of the load than the soil. 


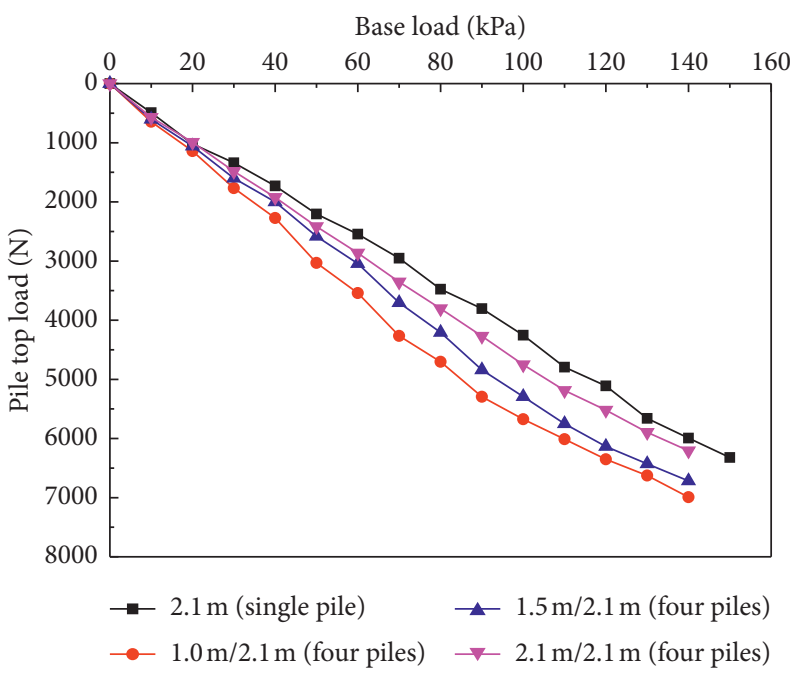

Figure 24: Pile top load of the long pile in the composite foundations.

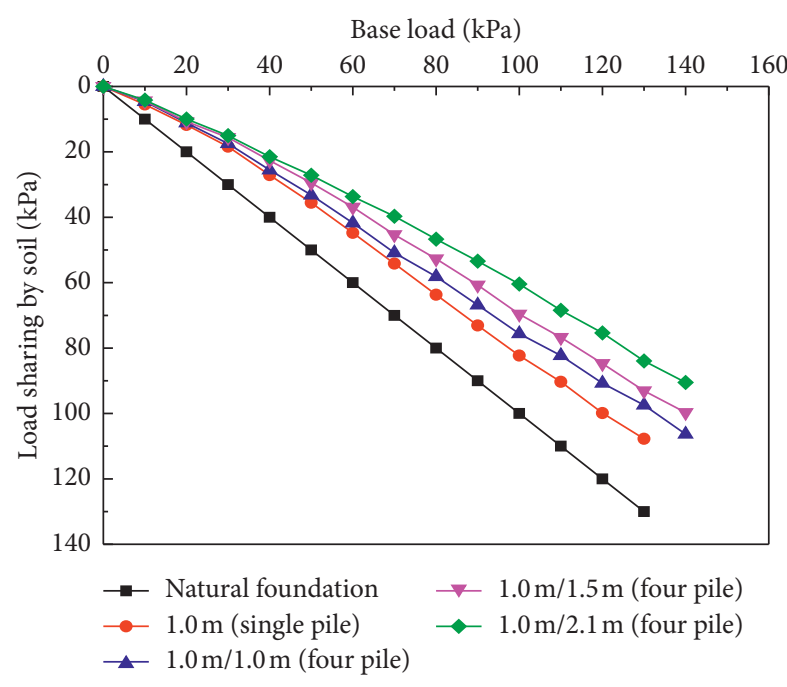

(a)

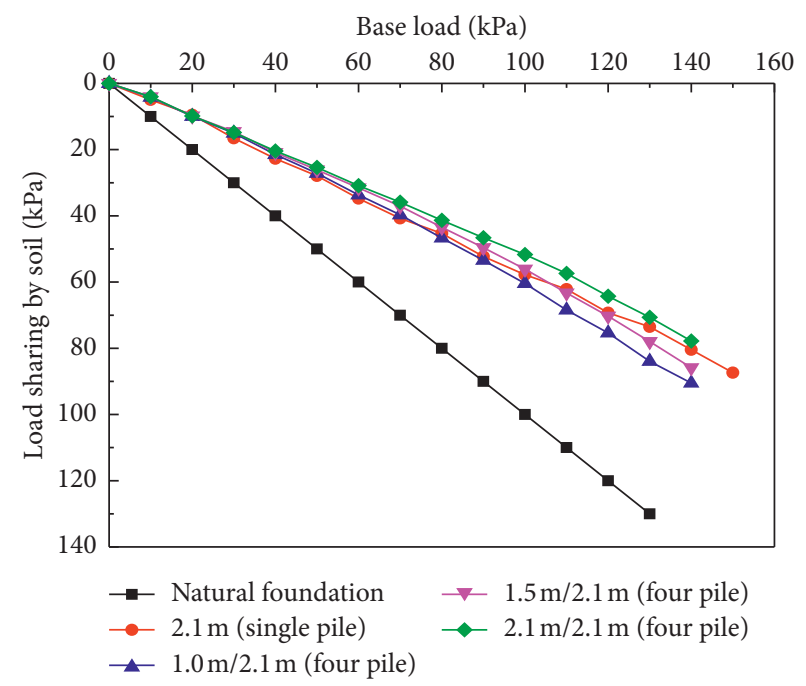

(b)

FIGURE 25: Load sharing by soil of the composite foundation. (a) Load sharing (short pile unchanged). (b) Load sharing (long pile unchanged).

The single-long pile composite foundation shows fluctuations in load sharing (Figure 25(b)). This is attributed to the relatively large rigidity of the single-pile composite foundation, and the small settlement under the same load, reducing the load-sharing contribution of the soil. However, due to the smaller size and greater rigidity of the single-pile than the four-pile composite foundation, the combined effect of the two factors causes fluctuations in the load sharing of the soil in the single-pile composite foundation.

\section{Conclusions}

In this study, the load transfer mechanism of a rigid longshort-pile composite foundation under a vertical load was systematically analyzed using three large-scale laboratory model tests. The main conclusions are as follows:
(1) The bearing capacity characteristic value of the single-long-pile composite foundation was about $50 \%$ higher than that of the single-short-pile composite foundation. When the pile length was less than the critical pile length of the end resistance, an increase in the pile length significantly improved the bearing capacity of the single-pile composite foundation.

(2) The maximum positive and negative frictional resistances of the single-long-pile composite foundation were 1 to 2 times higher, and the relative depth of the neutral point of the long-pile composite foundation was about $50 \%$ lower than that of the single short-pile composite foundation. The difference in negative friction at the top of the pile was caused by the compactness of the soil around the pile 
and the horizontal earth pressure on the side of the pile.

(3) Due to pile-soil interaction, the stiffness values of the pile and soil element of the four-pile composite foundation were lower than those of the single-pile composite foundation. Under the same load, the settlement of the four-pile composite foundation was relatively large, and the pile units shared the load. The influence of the long pile on the overall settlement was relatively large.

(4) We proposed an approximate analysis method to determine the stiffness distribution. The result of this method was consistent with the test results. The loadsharing of the soil and the stiffness of the soil element were primarily affected by the stiffness of the pile. The lower the stiffness of the pile, the higher the stiffness of the soil element.

(5) It is suggested to use a stiffness correction factor when calculating the pile-soil stiffness of the fourpile composite foundation based upon the pile-soil stiffness of the single-pile composite foundation. For the investigated composite foundation with four long and short piles, the overall stiffness correction coefficient was $0.7 \sim 0.8$, that of the short pile was $0.6 \sim 0.7$, that of the long pile was $0.85 \sim 0.9$, and that of the soil was $0.7 \sim 0.8$.

\section{Data Availability}

The data used to support the findings of this study are available from the corresponding author upon request.

\section{Conflicts of Interest}

The authors declare that there are no financial and personal relationships with other people or organizations.

\section{Acknowledgments}

This research was supported by the National Natural Science Foundation of China (No. 51508522).

\section{References}

[1] V. J. Sharma, S. A. Vasanvala, and C. H. Solanki, "Study of cushioned composite piled raft foundation behaviour under seismic forces," Australian Journal of Civil Engineering, vol. 13, no. 1, pp. 32-39, 2015.

[2] Y. S. Bie, M. Y. Liu, and Q. Zhang, "Numerical and stress analysis of composite foundation with long and short piles for the Hong Kong-Zhuhai-Macao bridge," Journal of Wuhan University of Technology, vol. 36, no. 5, pp. 101-105, 2014.

[3] H. Lu, Q. C. Gao, and B. Zhou, "Experimental research on bearing capacity of long-and-short pile composite foundation," Chinese Journal of Underground Space and Engineering, vol. 11, no. 1, pp. 56-63, 2015.

[4] T. Z. Ma, Y. P. Zhu, and X. H. Yang, "Bearing characteristics of composite pile group foundations with long and short piles under lateral loading in loess areas," Mathematical Problems in Engineering, vol. 2018, Article ID 8145356, 17 pages, 2018.
[5] P. Liu, G. H. Yang, and Y. C. Zhang, "Design method of longshort-pile composite foundation base on Tangent modulus in situ loading test curve," Advanced Materials Research, vol. 243, pp. 2314-2323, 2011.

[6] F. M. Abdrabbo and A. Z. El-wakil, "Behavior of pile group incorporating dissimilar pile embedded into sand," Alexandria Engineering Journal, vol. 54, no. 2, pp. 175-182, 2015.

[7] J. Lee, D. Park, and K. Choi, "Analysis of load sharing behavior for piled rafts using normalized load response model," Computers and Geotechnics, vol. 57, pp. 65-74, 2014.

[8] G. Mylonakies and G. Gazetas, "Settlement and additional internal forcent of grouped piles in layered soil," Geotechnique, vol. 48, no. 1, pp. 55-72, 1998.

[9] R. Rui, Y. Sun, and Y. Zhu, "Mesoscopic working mechanism of cushion of composite foundation under rigid slab," Rock and Soil Mechanics, vol. 40, no. 2, pp. 445-454, 2017.

[10] B. Leshchinsky, T. M. Evans, and J. Vesper, "Microgrid inclusions to increase the strength and stiffness of sand," Geotextiles and Geomembranes, vol. 44, no. 2, pp. 170-177, 2016.

[11] M. Yang and S. Liu, "Field tests and finite element modeling of a prestressed concrete pipe pile-composite foundation," KSCE Journal of Civil Engineering, vol. 19, no. 7, pp. 2067-2074, 2015.

[12] F. Yang, X.-C. Zheng, L.-H. Zhao, and Y.-G. Tan, "Ultimate bearing capacity of a strip footing placed on sand with a rigid basement," Computers and Geotechnics, vol. 77, pp. 115-119, 2016.

[13] Q.-Q. zhang, S.-W. Liu, R.-F. Feng, J.-G. Qian, and C.-Y. Cui, "Finite element prediction on the response of non-uniformly arranged pile groups considering progressive failure of pilesoil system," Frontiers of Structural and Civil Engineering, vol. 14, no. 4, pp. 961-982, 2020.

[14] J. J. Zheng, J. H. Qu, and N. Z. Yuan, “Analytical solutions of composite modulus of multi-element composite foundation by parametric variational principle," Journal of Geotechnical Engineering, vol. 25, no. 3, pp. 317-321, 2003.

[15] J. L. Yu, J. Z. Jin, and X. N. Gong, "Working behaviors of composite ground under flexible foundation based on supersub structure interaction," Chinese Journal of Geotechnical Engineering, vol. 32, no. 5, pp. 657-663, 2010.

[16] C. F. Wu and W. C. Guo, "Analysis of the soil arching effect between piles of rigid pile foundation and calculation of the pile-soil Stress ratio," Construction Technollogy, vol. 44, no. 1, pp. 67-72, 2015.

[17] C. F. Wu, W. C. Guo, and Y. N. Li, "Calculation of neutral surface depth and pile-soil stress ratio of rigid pile composite foundation considering influence of negative friction," Chinese Journal of Geotechnical Engineering, vol. 38, no. 2, pp. 278-287, 2016.

[18] Y. Gao, S. Yang, F. Zhang, and B. Leshchinsky, "Threedimensional reinforced slopes: evaluation of required reinforcement strength and embedment length using limit analysis," Geotextiles and Geomembranes, vol. 44, no. 2, pp. 133-142, 2016.

[19] J. J. Zheng and X. R. Peng, "Study on design theory of pile-soil cooperative work," Rock and Soil Mechanics, vol. 24, no. 2, pp. 242-245, 2003.

[20] P. Liu and G. H. Yang, "The calculating method for the pile length of composite foundation under rigid ground," Chinese Journal of Underground Space and Engineering, vol. 7, no. 6, pp. 1078-1085, 2011.

[21] W. Liu, X. H. Yang, S. S. Zhang, X. X. Kong, and W. Z. Chen, "Analysis of deformation characteristics of long-short pile 
composite foundation in salt lake area, Iran," Advances in Civil Engineering, vol. 2019, Article ID 5976540, 15 pages, 2019.

[22] X. C. Kang, S. J. Wang, and Q. Liu, "Analysis of pile-soil interaction of Gravel pile composite foundation," Electronic Journal of Geotechnical Engineering, vol. 21, no. 1, pp. 79-87, 2016.

[23] T. H. Zhou, F. Wang, and H. Zhao, "Bearing capacity tests on multi-type-pile composite foundation with rigid cap," Chinese Journal of Geotechnical Engineering, vol. 37, no. 1, pp. 105111, 2015.

[24] L. Qi, W. Liu, and C. S. Sun, "Model test research on load transfer mechanism of composite ground considering underlying layer features," Rock and Soil Mechanics, vol. 33, no. S1, pp. 123-128, 2012.

[25] J. Xiong, F. Li, X. Zhu, and M. Yang, "Model test of composite long-short pile foundation," Tongji Daxue Xuebao/Journal of Tongji University, vol. 36, no. 10, pp. 1337-1343, 2008.

[26] M. Q. Liu and D. Huang, "Numerical and theoretical study on the settlement of capped piles composite foundation under embankment," Advances in Civil Engineering, vol. 2020, Article ID 3978780, 17 pages, 2020.

[27] D. E. Ong, C. E. Leung, and Y. K. Chow, "Pile behavior due to excavation-induced soil movement in clay. I: stable wall," Journal of Geotechnical and Geoenvironmental Engineering, vol. 132, no. 1, pp. 36-44, 2006.

[28] D. E. L. Ong, C. F. Leung, and Y. K. Chow, "Behavior of pile groups subject to excavation-induced soil movement in very soft clay," Journal of Geotechnical and Geoenvironmental Engineering, vol. 135, no. 10, pp. 1462-1474, 2009.

[29] X. S. Ge, X. L. Zhai, and J. W. Xue, "Model test research of pile body modulus on the long-short-pile composite foundation," Advanced Materials Research, vol. 243, pp. 2300-2303, 2011.

[30] Y. C. Guo, S. H. Zhang, G. Shi, and N. Liu, "Optimization strategy of the Long-short-pile composite foundation based on the settlement control," Advanced Materials Research, vol. 243, pp. 2429-2434, 2011.

[31] P. Liu, G. H. Yang, and Z. Fan, "Experimental study on scale effect of rigid pile composite foundation," Chinese Journal of Rock Mechanics and Engineering, vol. 35, no. 1, pp. 187-200, 2016.

[32] Y. Hong, B. He, L. Z. Wang, Z. Wang, C. W. W. Ng, and D. Mašín, "Cyclic lateral response and failure mechanisms of semi-rigid pile in soft clay: centrifuge tests and numerical modelling," Canadian Geotechnical Journal, vol. 54, no. 6, pp. 806-824, 2017.

[33] China Planning Press, Standard for Geotechnical Test Method (GBT 50123-2019), China Planning Press, Beijing, China, 2019.

[34] D. E. L. Ong and C. S. Choo, "Assessment of non-linear rock strength parameters for the estimation of pipe-jacking forces. Part 1. direct shear testing and backanalysis," Engineering Geology, vol. 244, pp. 159-172, 2018.

[35] C.S. Choo and D. E. L. Ong, "Assessment of non-linear rock strength parameters for the estimation of pipe-jacking forces. Part 2. Numerical modeling," Engineering Geology, vol. 265, 2020.

[36] China Architecture \& Building Press, Technical Code for Testing of Building Foundation Piles (JGJ 106-2014), China Architecture \& Building Press, Beijing, China, 2014. 